UNIO - EU Law Journal. Vol. 4, No. 2, July 2018, pp 48-60.

(2018 Centre of Studies in European Union Law

School of Law - University of Minho

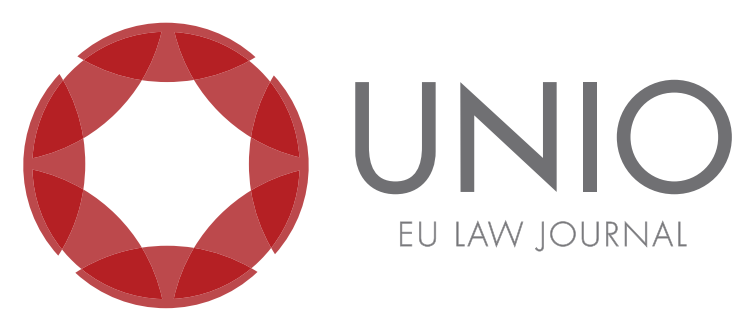

\title{
Digital Single Market as the new world to the European Union: repercussions in social and institutional regulatory structure - the universal service and the Body of European Regulators for Electronic Communications' (BEREC) re- definition
}

Joana Covelo de Abreu*

ABSTRACT: Digital Single Market is the new world in the EU and it is perceived as primary public interest because it was one of the ways the EU found to become more financially attractive and better suited to innovation. To accomplish that, several legal solutions appear to be unsuitable for the present time EU is living in. Concerning electronic communications, its legal and regulatory framework needed to be recasted and a new Electronic Communications Code proposal was made by the European Commission. Among many innovative solutions, it aims at redefining EU universal service, to update it to connectivity solutions of our time, and at revising the Body of European Regulators for Electronic Communications' role, granting it further competences on crossborder dispute resolution and articulation between European institutions and national regulatory authorities. These dimensions rethink both social and institutional regulatory framework and this text wants to understand what their strengths and weaknesses are.

KEYWORDS: Digital Single Market - Electronic Communications - Regulatory Framework - Universal service - BEREC.

\footnotetext{
* Professor at the School of Law of the University of Minho. Team member of the Jean Monnet Project "INTEROP - EU Digital Single Market as a political calling: interoperability as the way forward" funded by EACEA (Education, Culture and Audiovisual Executive Agency).
} 


\section{Information and Communication Technologies (ICT) impact in global economic relations and the Digital Single Market's implementation as a primary public interest}

The internet is the space where economic, political, social, cultural, and recreational dimensions appear assembled together, making different paradigms cohabit with each other. This reflexion aims at dealing with the idea and the functioning of the internet as a phenomenon's facilitator - the one related to globalization - with economic repercussions that cannot be undermined and forgotten.

In fact, the globalization phenomenon (or concerning those relations that overcome frontiers) is already an outdated scheme but it has profoundly increased, and it was potentiated - to a new scale, effectively global - with the generalization of digital tools. That digital input allowed markets - in all economic sectors - to reinvent themselves and to explore new ways of supply and demand, new ways of commercialization, new publicity and marketing platforms, etc. This is what we can call "the new world", as an apology to Terrence Mallick's cinematographic work with the same title. In fact, facing a new reality - and despite the historical period when it comes into light - there are new demands to answer, it is needed to embrace new horizons and perspectives and there are legal and political changes that are inherent to the new status quo.

In this light, and taking into consideration this reality, it is up to this exploratory study to verify and expose how the EU has been addressing these new perspectives concerning economic globalization and the innovative role ICT had on the matter. In fact, these new political angles are going to have strong impact both on economic and legal setting.

Taking into account this sensitivity, the EU bet on establishing the Digital Single Market as the novelty on the political domain, perceiving it as one of its main priorities under the Europe 2020 Strategy $^{1}$ - and all national and European political agents are congratulating themselves on its settlement since they are aware that "[o]nline platforms have dramatically changed the digital economy over the last two decades and bring many benefits in today's digital society". ${ }^{2}$ Digital Single Market appeared as one of the primary public interests because the European institutions became aware ICT tools and technological solutions "play a prominent role in the creation of 'digital value' that underpins future economic growth in the EU" ${ }^{3}$ and "Europe has a thriving start-up community with dynamic entrepreneurs targeting new opportunities". ${ }^{4}$ Notwithstanding, the European Commission concluded that "[a] number of globally competitive platforms originated in Europe, for example Skyscanner and BlaBlaCar" but, "on the whole, the EU currently represent $[s]$ only $4 \%$ of the total market capitalisation of the largest online platforms". 5

Therefore, the Commission understood the EU should become a place sufficiently attractive to economic agents to domicile their businesses. In fact, ICT

\footnotetext{
${ }^{1}$ See European Commission, Commission Staff Working Document "A Digital Single Market Strategy for Europe - Analysis and evidence", Communication from the Commission to the European Parliament, the Council, the European Economic and Social Committee and the Committee of the Regions - "A Digital Single Market Strategy for Europe”, SWD(2015) 100 final, Brussels, 6 May 2015, 3.

${ }^{2}$ See European Commission, Communication from the Commission to the European Parliament, the Council, the European Economic and Social Committee and the Committee of the Regions - "Online platforms and the Digital Single Market. Opportunities and Challenges for Europe", $\operatorname{COM(2016)~} 288$ final, Brussels, 25 May 2016, 2.

${ }^{3}$ See European Commission, Online platforms..., 2.

${ }^{4}$ See European Commission, Online platforms..., 3.

${ }^{5}$ See European Commission, Online platforms..., 3.
} 
solutions can promote growth, development and employment in the EU. That derives from ICT's characteristics - their usage allows their users to be seamlessly reached, and in an easier manner, redefining the economic structure as we have known it for many years. Digital supply enables one to reach the final user in an easy and effective way and with an instant impact - despite being a buyer, a supplier, a common citizen trying to keep up with the latest news... Therefore, digital components started to " [...] cover a wide-ranging set of activities including online advertising platforms, marketplaces, search engines, social media and creative content outlets, application distribution platforms, communications services, payment systems and platforms for the collaborative economy". ${ }^{6}$ With a click, all goods and services can be acquired, even if their supplier is on the other side of the globe.

The EU started to stress its worries on promoting a more receptive environment to ICT tools when it concluded, through data advanced by the European Commission, that it has only a marginal impact, on a global scale, on technological and digital development. In fact, the European Commission mentions the following: "on the whole, the EU currently represents only $4 \%$ of the total market capitalisation of the largest online platforms: the vast majority of platforms originate in the US and Asia".

Bearing in mind those numbers, the EU understood its Member States must create the essential environment and framework so that new online platforms can emerge and are able to choose the EU to settle. Furthermore, EU also had to think of new approaches to allow economic agents already installed there to globally grow, taking into consideration small and medium enterprises (SMEs). Only this would allow productivity gains in the future.

To achieve it, the EU settled a Digital Single Market strategy ${ }^{8}$ which, at potentiating citizens and companies to develop their activities online, wanted to pursue free competition while achieving a higher standard of data and consumers' protection. Otherwise, a setback on European values would occur and that must not be the path to follow.

In fact, betting on a more open space to digital and technological components facilitates the citizens in new ways to access information and culture. It can also lead to an "open government, equality and non-discrimination"; and "[i]t can create new opportunities for citizens' engagement in society at large, including democratic participation [... ]". 'The EU is trying to reinvent itself through a digital Europe where digital means can be used and embraced by the population at large and companies are able "to make full use of ICT to scale up for productivity gains, creating growth along the way". ${ }^{10}$ As Mr. Malcolm Harbour, Member of the European Parliament, stated: "the Digital Single Market is the Single Market, because if you now look at every single business that accesses the single market one of its strong components will be the Internet or an electronic-base offering".

Bearing this construction in mind, the EU promoted a stakeholders' forum the 2016 Digital4EU - where, in a first approach, the Digital Single Market's fate was under scrutiny. Its session 1, under the topic "Delivering the Digital Single Market - from the Digital Economy and Society Index (DESI) to action", the stakeholders made four central inputs: 1) To stimulate connectivity; 2) To enhance the digital skills of involved human capital; 3) To stimulate the integration of digital technology by

\footnotetext{
${ }^{6}$ See European Commission, Online platforms..., 2.

${ }^{7}$ See European Commission, Online platforms..., 3.

${ }^{8}$ See European Commission, Commission Staff Working Document...

${ }^{9}$ See European Commission, Commission Staff Working Document, 3.

${ }^{10}$ See European Commission, Commission Staff Working Document, 3.
} 
firms; and 4) To bet on digital public services. ${ }^{11}$ In the concrete case, a reflexion was demanded concerning the impact of the Digital Single Market implementation on the regulatory setting of electronic communications to understand which main changes were to be incorporated. Under the topic "connectivity", stakeholders perceived it as paramount to "establish an environment promoting investments as part of the current telecom regulatory review" to achieve better economic performance in the EU.

However, the context and the legal framework of the new regulatory system had to be "clear, predictable and flexible" so that Member States could easily adapt it to their own specificities. ${ }^{12}$ In the same sense, stakeholders are shown the need to enlighten when, and under which conditions, the intervention of regulatory entities was going to be necessary, since stakeholders understood that regulatory intervention and supervision should be set by activity and not by taking into consideration which economic agents are involved. In this matter, the rhythm is unknowingly fast, and solutions must be set in motion as soon as possible. Furthermore, stakeholders also named as being vital to "give the right incentives for companies" where "s $s]$ tate aid is crucial for uncovered areas where there is no business case"13 and, particularly, to stimulate innovation. In fact, these were the basis to the co-investment idea (recently adopted by the European Parliament on the matter).

Stakeholders also understood there is work to be done concerning those who compose the demand side: there is a clear need to enhance people's digital skills, betting on new ways of digital contact with citizens by the political power, and stimulating e-commerce through an enlarged feeling of online security.

Therefore, the engaged stakeholders - among which was the European Consumers Organization (BEUC) - saw such regulatory framework as a promoter of cross-border commerce and not as a contention element, focusing on: i) the developed activities and not only on the economic agents behind them; ii) creating regulatory measures that can be feasible concerning ICT activities; iii) a system that is at the service of economic agents' protection; iv) promoting innovation; and; v) following a neutral action. ${ }^{14}$

In this sense, it was understood there are several developments to make in telecommunications and electronic communications regulation framework, but some doubts remained on how to address it in terms of execution and fulfilment. The greatest problem, notwithstanding, relies on the fact these approaches are being led locally despite the realities at stake, bearing in mind a more globalized, interconnected, and interoperable interaction where the action of a sole regulatory authority with a national scope of action will not be enough or even adequate. For instance, Annabelle Gawer "questioned the role of regulation where the companies like online platforms are global actors, but the enforcement of regulation is local'. ${ }^{15}$

Furthermore, it is important that regulation focuses itself on activities and not on a special business - in fact, a new regulatory framework cannot appear as new online platforms appear; it is needed to assess if that is, in fact, a new activity or, on the other hand, a former one with a new approach and, therefore, already

\footnotetext{
${ }^{11}$ See European Commission, Digital4EU 2016 Stakeholder Forum Report, Brussels, 25 February 2016, $13-14$.

${ }^{12}$ See European Commission, Digital4EU 2016, 13.

${ }^{13}$ See European Commission, Digital4EU 2016, 13.

${ }^{14}$ See European Commission, Digital4EU 2016, 21.

${ }^{15}$ See European Commission, Digital4EU 2016, 20.
} 
under the scrutiny of the existing framework. It is on this matter that updating the regulatory setting gets particularly hard - the supply on digital domains appears in such a rhythm that makes law fields to be running against the time. To overcome this difficulty, there has to be greater consistency on the application of existing rules by both the EU and the Member States.

Having this said, it is important to understand how solutions are being devised.

\section{Digital Single Market implementation and the issue concerning online platforms regulation}

To answer stakeholders' worries, namely to regulate the activities and not the economic agents, the European Commission adopted its Communication under the theme "Online Platforms and the Digital Single Market - opportunities and challenges for Europe", where it started to address important features concerning online platforms. In fact, without having the conductive line about which characteristics are going to be used to define an online platform, it becomes quite difficult to set the path the regulatory authorities must follow and, furthermore, which are the matters under regulation.

It is relevant to establish that online platforms have some immanent characteristics that will allow us to foresee if there is a new activity or if it is a new agent developing the same activity, previously submitted to the action of a regulation framework. Therefore, "online platforms share some important and specific characteristics": 1) "they have the ability to create and shape new markets", challenging "traditional ones, and to organise new forms of participation or conducting business based on collecting, processing, and editing large amounts of data"; 2) they are able to act in multifaceted markets; 3) they can be beneficiaries of the so-called "network effects" ${ }^{3}$; 4) they use ICT tools to reach users in a instant and effortless way; and 5) they are able to create digital value, usually relying on "data accumulation" in order to promote new business offers. ${ }^{17}$

Their benefits were already addressed but the Commission also stressed its worries: "[...] the growing importance of the digital economy linked with the diversity and fastchanging nature of platform ecosystems also raise new policy and regulatory challenges". ${ }^{18}$ In order to achieve the full potential of the Digital Single Market in the EU, namely to " [... reap the full benefits from the platform economy and [to] stimulate growth in European platform start-ups", it is important that a harmonized set of rules for all Member States is established as "[d]iffering national or even local rules for online platforms create uncertainty for economic operators, limit the availability of digital services, and generate confusion for users and businesses". ${ }^{19}$

That has gradually been met on competition, protection of personal data, consumer protection, and economic freedoms' observance. But it also must bear in mind the needed follow-up on enforcement. In fact, digital platforms have a cross-border configuration which demands a further cooperation between national relevant authorities. This matter is already being pursued through the GDPR ${ }^{20}$, when

\footnotetext{
${ }^{16}$ In a short version, and as mentioned by the European Commission, "network effects" describe the market appreciation of the service through the number of users - "the value of the service increases with the number of users". See, for further detail, European Commission, Online platforms..., 2.

${ }^{17}$ See, for further development, European Commission, Online platforms..., 2 and 3.

${ }^{18}$ See European Commission, Online platforms..., 3.

${ }^{19}$ See European Commission, Online platforms..., 4.

${ }^{20}$ See Regulation (EU) 2016/679 of the European Parliament and of the Council, of 27 April 2016,
} 
it demands national and European entities to be articulated on data protection issues. The same sensitivity must be present in other material sectors, such as the electronic communications regulatory framework.

The Commission also understood that further measures to be considered must "only address clearly identified problems relating to a specific type or activity of online platforms in line with better regulation principles". ${ }^{21}$ It is, therefore, foreseen as fundamental that equal conditions to comparable digital services should be met to promote an adequate and updated regulatory framework that could answer these new challenges posed by online platforms.

This path comes strictly connected to the belief that there are online platforms operators which offer services that can functionally substitute themselves for other forms of traditional nature. The paradigmatic example is the one of those "Over-TheTop" (OT'T) applications. "Over-The-Top" (OT'T) applications gain huge interest due to their competitive service offer towards the telecommunication provider and operator"22. In fact, "[n]etwork (cloud) storage, news, social networks as well as classic telco provider services as voice, video and messaging are offered alternatively and partially for free". ${ }^{23}$

OTT applications directly compete with traditional telecommunications' providers. In fact, OTT applications have the same characteristics as those of traditional services but the former are not bound to the same rules as the latter. OTT gained particular importance because they reinvented the mobile area, they challenge "the telecommunication business in the domain of voice, video and messages and finally reduces the operator business to a pure IP connectivity provider" and "OTT services mainly rely on proprietary solutions, without taking interoperability into consideration" 24 and as stated by the doctrine on the matter, "[u] sually the communication offered to a subscriber of a OTT services (Skype, Facebook, Google, Whats App, etc.) is limited to other subscriber of the same system, but not include subscribers of other OTT services". ${ }^{25}$

Bearing this conclusion in mind, it became clear that equal conditions to comparable service providers were needed - the idea was to avoid overburdening both emerging and traditional markets to create, on regulatory terms, a nondiscriminatory regime with the ability to be equally applicable. So, before comparable digital services, similar and equivalent rules must be adopted. It is a fact that what can be perceived as a "comparable service may vary with the public policy context" but this is another reason to establish a general principle of the Digital Single Market on the matter - the one called, by the European Commission, as the principle of the "level playing field" - which can be achieved by simplifying, modernising and enlightening existing regulation without "imposing a disproportionate burden on new as well as traditional business models". ${ }^{26}$

Following this demand, the European Commission presented, on the $14^{\text {th }}$ September 2016, a Directive's proposal establishing the European Electronic

on the protection of natural persons with regard to the processing of personal data and on the free movement of such data, and repealing Directive 95/46/EC (General Data Protection Regulation).

${ }^{21}$ See European Commission, Online platforms..., 5.

${ }^{22}$ See Marius Corici et al., "Network and control platforms", in Evolution of telecommunication services - the convergence of telecom and internet: technologies and ecosystems, ed. Emmanuel Bertin, Noel Crespi and Thomas Magedanz (Springer: Heidelberger, 2013), 18.

${ }^{23}$ See Marius Corici et al., Network and control platforms, 18.

${ }^{24}$ See Marius Corici et al., Network and control platforms, 18.

${ }^{25}$ See Marius Corici et al., Network and control platforms, 18.

${ }^{26}$ See European Commission, Online platforms..., 5. 
Communications Code..$^{27}$ This proposal came into light since the regulatory framework for electronic communications was last revised in 2009 and it needed recast since "the sector has significantly evolved and its role as an enabler of the online economy has grown". ${ }^{28}$ In fact, both citizens and businesses are more dependable on data and internet access services "instead of telephony and other traditional communication services". ${ }^{29}$ This allowed new market players and providers to compete with traditional communication services - as those of OTT applications. ${ }^{30}$ Furthermore, it is a proposal that aims at meeting another Digital Single Market public interest: The Gigabit Society's implementation. ${ }^{31}$

More recently, in February 2018, the European Parliament issued a briefing under the topic "EU electronic communications code and co-investment: Taking stock of the policy discussion". ${ }^{32}$ It is a document that seeks to follow the Directive's proposal, to pursue, both, the Gigabit Society's implementation and the stakeholders' demands on finding a way of promoting private investment engagement. For this purpose, the European Parliament is betting on co-investment as the way to meet those goals, setting aside state aid as the formula to meet further efficiency.

Laying our attention on the Directive's proposal, we can see it is quite ambitious and it aims at accomplishing the observance of general principles of competition law in the EU. Among several proposals in the electronic communications regulatory framework, we want to highlight two, one of which is material and another of institutional character:

- on one hand, it looks for a redefinition of the universal service that is assured in all Member States of the EU;

- on the other hand, it bets on the redefinition of the role of the Body of European Regulators for Electronic Communications (BEREC), giving it, in articulation with a Regulation's proposal, consultative ability and particular power on cross-border dispute resolution and with technical advisory influence.

Taking these two issues under further analysis, we will try to perceive which main changes will arise from the proposed new Electronic Communications Code.

\section{a. Universal service redefinition under the Directive's proposal establishing a European Electronic Communications Code}

It is up to the regulatory scheme to promote, alongside with the fair competition between economic agents, the so-called social regulation. This social regulation, when it comes to electronic communications, directly relates to the universal service.

\footnotetext{
${ }^{27}$ See European Commission, Proposal for a Directive of the European Parliament and of the Council establishing the European Electronic Communications Code, Brussels, COM(2016) 590 final, 14 September 2016, with the recast (on the English language version) of 12 October 2016.

${ }^{28}$ See European Commission, Proposal for a Directive..., 2.

${ }^{29}$ See European Commission, Proposal for a Directive..., 2.

${ }^{30}$ As mentioned in the Directive's Proposal, "e.g. so called over-the-top players (OTTs): service providers offering a wide variety of applications and services, including communications services, over the internet". For further development, see European Commission, Proposal for a Directive..., 2.

${ }^{31}$ See Joana Covelo de Abreu, "Promotion of internet connectivity in local communities ("WiFi4EU" legislative framework): deepening European Digital Single Market through interoperability solutions Editorial of October 2017”, in UNIO - EU Law Journal - The official blog, in https: / officialblogofunio. com/2017/10/09/editorial-of-october-2017/\#more-2265 [access: 5.5.2018].

${ }^{32}$ See European Parliament, Briefing "EU electronic communications code and co-investment: Taking stock. of the policy discussion”, 5 February 2018, in http://www.europarl.europa.eu/RegData/etudes/ BRIE/2018/614693/EPRS_BRI(2018)614693_EN.pdf [access: 20.3.2018].
} 
Social regulation appears, therefore, as a need to promote the rights and interests of the users, despite their geographical location.

In this context, national regulatory authorities must ensure that all users have access to the universal service. The concept of universal service is dynamic: it stands for minimum services of specified quality, available to all users despite their geographical location and, taking into consideration national conditions, at an accessible price. Therefore, " $t$ the universal service rules ensure that every user can access basic communication services at a reasonable quality and an affordable price, even if the market would not provide if'. ${ }^{33}$

As a dynamic concept, it must be subjected to an evolutionary reading so it can accompany technological progress, the market's development and the users' search modifications. Its main feature is its geographical ubiquity - all users, despite their geographical location, must access the service in an equal manner. This quality is important because it enables economic agents to differentiate isolated communities (where consumers' interest is low and, therefore, do not see it as a profitable avenue to pursue) and central communities (where profit is a reality).

Concerning the regulatory framework still in force, it is up to national regulatory authorities to control the prices of those services under the universal service to promote and allow higher connectivity and accessibility. However, it cannot be mistaken with a public service - since the notion of universal service connects itself to a public assurance responsibility demanding the State to ensure that certain services are going to be provided, before special conditions, by the market. The provision of those services represents, to some extent, a burden on the suppliers, demanding that they be the ones to provide that service following predetermined rules and not the normal market conditions (set by availability of the service taking into consideration the demand observed).

As a dynamic concept, the Commission's proposal aims at gradually adapting universal service to the new reality: setting affordable fixed voice communications and basic broadband internet services. The proposal only bets that this access focuses itself, on a first approach, on fixed voice and broadband services - but it invites Member States to adopt further legislative and regulatory measures that can "include affordability measures for mobile services for the most vulnerable end-users" 34 . To accomplish that, the proposal aims at mobilizing political stimulation mechanisms such as through "incentives to private investment, state aid, spectrum-related coverage obligations, etc." in order to achieve, under the redefinition of universal service, what they call "universal broadband".35

Therefore, the proposal wants to modernize the universal service regime, focusing on a universal broadband service. Member States intervention must focus more on promoting the economic accessibility of available connectivity. In this context, the proposal entrusts to Member States and their national regulatory authorities the obligation to adhere to the promise that they are going to assure, to all end-users, affordable prices to broadband internet connection and voice services, through a fixed location. To maintain that economic affordability, the proposal allows Member States to demand from economic agents the offer of special price options

\footnotetext{
${ }^{33}$ See European Commission, Universal Service, last updated 8 June 2018, in https://ec.europa.eu/ digital-single-market/en/content/universal-service-0 [access: 27.6.2018].

${ }^{34}$ See European Commission, Proposal for a Directive..., 11.

${ }^{35}$ See European Commission, Proposal for a Directive..., 11.
} 
for the most vulnerable end-users.

Furthermore, in a way to promote legislative adequacy, the Commission's proposal also perceives the need to set aside some demands which are no longer adequate: to meet this, the Commission proposes changes such as "the removal of redundant universal service obligations such as requirements to ensure the provision of payphones and physical directories" and "narrowing of the scope of universal service availability obligations and ending of the sectorial sharing mechanism". ${ }^{36}$

In Portugal, ANACOM (National Authority for Communications) is responsible for the electronic communications sector's regulation and, specifically, coordinates with the Government in order to maintain the universal service. However, taking into consideration this EU regulatory framework revision, it is predictable national legislation concerning electronic communications ${ }^{37}$ that will need to be significantly revised, namely on universal service's definition in order to deal with those novelties that were previously addressed.

Only time will allow one to understand if these changes will meet the daylight despite being clear that solutions to a more effective social regulatory framework will be able to realise the Digital Single Market's full potential.

\section{b. The redefinition of BEREC's role}

In the proposed European Code for Electronic Communications, the European Commission bets on strengthening relations between BEREC and national regulatory authorities by understanding BEREC as an effective decentralized regulatory agency.

Agencies are different EU offices, diverse from its institutions and bodies, which are legal entities created to fulfil specific tasks under EU law. They have main technical competences to overcome national authorities' doubts. They are legal entities created to develop specific tasks under EU law. In this case, "[t] he reasons for targeted strengthening of regulatory oversight mainly through an enhanced role of BEREC is justified on the basis of evidence of a lack of consistency in the implementation of regulation, which is key for promoting the internal market". ${ }^{38}$ BEREC is given additional tasks as a decentralised agency, taking an advisory role with certain normative powers. It will bring Member States and their national regulatory authorities to jointly act with the European institutions to implement European public political options - namely on shared competences matters - allowing better cooperation and sharing of technical competences.

As these bodies and agencies do not follow a single model, they all rely on their own "constitutive charter". In BEREC's case, the proposed Electronic Communications Code sets in motion the adoption of other legislative proposals, namely a Regulation's proposal establishing the Body of European Regulators for Electronic Communications $^{39}$. This Regulation is an instrumental act to the European Electronic Communications Code proposal since the latter entrusts to BEREC the fulfilment of some tasks that will allow the coherent application of the regulatory setting.

\footnotetext{
${ }^{36}$ See European Commission, Proposal for a Directive..., 13 and 14.

${ }^{37}$ See Law No. 5/2004, 10 February, also known as "REGICOM - Regime Geral das Comunicações Eletrónicas", available, in portuguese, in http://www.pgdlisboa.pt/leis/lei_mostra_articulado.php?ni $\mathrm{d}=1439 \&$ tabela $=$ leis\&ficha $=1$ \&pagina $=1 \&$ so_miolo $=\&$ [access: 27.6.2018]

${ }^{38}$ See European Commission, Proposal for a Directive..., 5.

${ }^{39}$ See European Commission, Proposal for a Regulation of the European Parliament and of the Council establishing the Body of European Regulators for Electronic Communications, COM(2016) 591 final, Brussels, 14 September 2016.
} 
Therefore, despite having been institutionally created in 2010 (becoming operational in 2011), BEREC offered technical support to national regulatory authorities and to European institutions, namely through opinions. For these reasons, its role appeared as needing to be reinforced but maintaining the same designation. Among several competences and tasks, BEREC will have to create a register for the extraterritorial use of numbers and cross-border arrangements. It will also have to create another EU register of providers of electronic communications networks and services.

It will be asked to assist the European Commission and national regulatory authorities in standardisation, namely by helping them to identify if there is a lack of interoperability or a threat to end-to-end connectivity or if the emergency services' effective access is endangered. It will also act, in general authorisation procedures, as a single contact point. Therefore, operators must submit their notification to BEREC, which will forward it to national regulatory authorities. To facilitate those contacts, BEREC must create a European register. ${ }^{40}$ BEREC will also have consulting tasks, namely on giving guidelines on best practices in conducting geographical surveys of networks roll-out. ${ }^{41}$

Furthermore, under Article 2(3) of the Regulation's proposal establishing BEREC, it is stated national regulatory authorities "shall comply with any decision and take the utmost account of any opinion, guideline, recommendation and best practice adopted by BEREC with the aim of ensuring a consistent implementation of the regulatory framework for electronic communications".

On the other hand, under Article 27 of the Electronic Communications Code proposal, a mechanism of cross-border dispute resolution between undertakings in different Member States is created. Here, the role of BEREC is consolidated since national regulatory authorities will notify the dispute to BEREC "in order to bring about a consistent resolution of the dispute".

Therefore, the Regulation's proposal aims at accomplishing regulatory goals the Commission established in the strategy it designed for the Digital Single Market. So, concerning BEREC, its role's recast wants to assure an institutional regulatory framework that can be more effective so that electronic communications setting is adequately applied to proceed with their role on creating the propitious conditions to setting a Digital Single Market. In fact, as meaningfully advances will arise on market conditions and technological environment, there is a need to reinforce the institutional setting, namely enlarging the BEREC's scope of action.

Concerning BEREC's role, the European Parliament also addressed its situation in the briefing "Body of European Regulators for Electronic Communications (BEREC)" 42 where it understood "the administrative capacity of BEREC needs to increase" since "[i]ts current architecture is made up of a body with legal personality (BEREC Office), which is (in terms of staffing) the smallest agency-like entity in the EU, plus the BEREC board of regulators". ${ }^{43}$ In this sense, the European Parliament understood that the required legislative conditions which would lead to a coherent application of the regulatory framework

\footnotetext{
${ }^{40}$ See European Commission, Proposal for a Directive..., recital 40.

${ }^{41}$ See European Commission, Proposal for a Directive..., recital 60.

${ }^{42}$ See European Parliament, Briefing "Body of European Regulators for Electronic Communications (BEREC)", 23 June 2017, in http://www.europarl.europa.eu/RegData/etudes/BRIE/2016/593560/EPRS_ BRI\%282016\%29593560_EN.pdf [access: 20.5.2018].

${ }^{43}$ See European Parliament, Briefing “Body...”, 2.
} 
on electronic communications, could be achieved by an effective supervision made by BEREC, namely by deepening its consultative competences on cross-border dispute resolution.

In fact, it has become clear that, besides an evident market's fragmentation, there is also a lack of coherence on the electronic communications regulatory setting. Both negative assessments are due, at least in part, to the contemporary institutional frameworks and the way several institutional agents (namely national regulatory authorities, BEREC and the European Commission) interact and can influence the final regulatory setting's effectiveness. Therefore, BEREC's ex ante reinforced regulatory powers will provide further legal certainty and greater regulatory coherence. In fact, technological evolutions bring several cross-border issues which demand coincident frameworks applicable by different Member States. Therefore, a European entity will be able to better address those issues than each isolated Member State. However, there is a proportionality assessment since the new BEREC will continue to combine its competences with those allocated to national regulatory authorities (which continue to be the core of BEREC's action and constitute the members of its administration).

In this sense, the administrative and management structure of BEREC is based on 1) a management board; 2) an executive director; 3) working groups and 4) a board of appeal (Article 3 of the Regulation's proposal). The management board will be composed of one representative from each Member State and two representatives of the Commission, all with voting rights. It will be up to national regulatory authorities to nominate their respective representative amongst their members - Article 4(1). When there is more than one national regulatory authority per Member State, those will agree on a common representative, ensuring he/she will maintain the necessary coordination amongst them - Article 4(1)(2).

Under Article 4(3), its members will be appointed, taking into consideration their knowledge in the field of electronic communications, bearing in mind their managerial, administrative and budgetary skills. The terms will be four years and they can be re-constituted after their term ends if the BEREC wishes to retain them Article 4(4).

The executive director will manage BEREC and he/she will be accountable before the Management Board - Article 9(1). He/she will develop his/her functions with independence and autonomy, and he/she can neither seek nor take instructions from any government, institution, person, or body - Article 9(2).

Working groups are set up by the Management Board when there is a need to implement the working programme of BEREC - Article 10(1). Its members will be appointed be the Management Board among the experts of the national authorities, the Commission, BEREC's staff and of the third countries' national regulatory authorities that participate on BEREC's activities - Article 10(2). Their coordination and moderation will be ensured by a member of BEREC's staff - Article 10(3).

The Board of Appeal will know the appeals of BEREC's decisions which can be presented by any natural or legal person, including national regulatory authorities. For this purpose, the legitimate person/entity is either the addressee of that decision or, although the decision is addressed to another person, it is of direct and individual concern to that person - Article 14(2). These appeals will not, in general, have suspensory effect - Article 14(3).

Therefore, this legislative solution tackles, in an aprioristic manner, some 
difficulties that can emerge, in an integrated market, especially when they can assume cross-border manifestations as the EU is looking to harmonize the way regulatory dispositions are applied in all Member States.

\section{Final remarks}

From previous considerations it is easy to understand there is the new world which will determine how the EU's economy will be shaped in the future - through an effective bet of spreading technical and digital knowledge.

However, this demands a focused attention so that the regulatory paradigm can be maintained and its framework can be updated to these new realities...that new world... Regulatory demands, as we know them today, state that it is up to national regulatory authorities to control the market and to intervene so that some goals they are mandated to fulfil are met. Therefore, both the European Commission and other specialised bodies have the role of supervision and specialised technical monitoring.

In the electronic communications' regulatory framework, there are major changes we had the chance to address. Firstly, there is the Directive's proposal establishing a European Electronic Communications Code. It aims to address the vital role electronic communications have on European economy with a particular focus on social and institutional worries.

This Directive's proposal widens the notion of universal service on electronic communications. In fact, a harmonized demand of universal service is important to promote economic agents' non-discriminatory treatment and to widen and update services understood as universal under the new developments on electronic communications.

In this changing context, universal service will have to presuppose a broadband internet service - of fixed nature, at least - in a perspective of geographical omnipresence in all Member States. The proposal innovates on the type of universal service, but it also demands the settlement of capable infrastructures that can answer this new universal service. However, a topical approach on this proposal raises two main concerns:

- In the EU context, interest representation is a legally binding practice and it can determine this kind of solution if the costs associated are too high to economic agents that act within the electronic communications' market;

- Legally, it seems that this initiative can be a victim of the same reasons that led the recast we are addressing. In fact, the Electronic Communications Code proposal is not sufficiently concrete - nor even remits to other legal acts where the topic is dealt with - how electronic communications' economic agents will be subdued to the observance of this new universal service. In fact, we previously have addressed the difficulty concerning making new electronic communications' activities - such as those led by OTT - to be bound by the social regulatory framework. If there is not a further concretisation, traditional operators will continue to be those that are most burdened since they will continue to be the ones to support the costs inherent to creating the needed conditions to establish this new universal service.

Only time will be able to tell us how things are going to work but it seems the solution continues to treat differently those that, with the digital revolution, are equal or, at least, comparable and, for that matter, the goal set by this legislative pack seems undermined. When further information is gathered, it is important to understand if this is going to be the solution and which will, in practice, be its consequences. 
On the other hand, on institutional terms, BEREC is going to suffer a reconfiguration and will appear as an agency. In fact, bearing in mind the important role it already plays, it was foreseen to have a more prominent role so it can better contribute to meet EU goals and policies, especially by settling cross-border disputes and promoting a cross dialogue between European institutions and national regulatory authorities.

Our time is a paradigmatic historical period and the legal framework must be sufficiently scalable to answer new challenges. However, it is important to legally act fast as innovation in all other sectors is occurring. This is the new challenge EU law must face and tackle. 